\title{
SONEAR: SONIFICAR, SONORIZAR Y AUDIFICAR. TRANSFORMACIONES DEL CAMPO ELECTROMAGNÉTICO EN EL ARTE
}

\author{
Alejandra Bueno de Santiago
}

Universidad San Gregorio (Ecuador)

\section{Resumen}

La utilización de lo cotidiano en el arte cambia; actualmente es la tecnología y sus extensiones electrónicas quienes están bajo este marco. El paso de lo analógico a lo digital ha generado un nuevo elemento de trabajo, una materia no perceptible transmitida por el aire. Nos relacionamos con más máquinas que con personas, y estas no hablan pero generan energías y vibraciones, un segundo nivel de interacción máquina-usuario. Las energías nos atraviesan y podemos ser sensibles o no, o mejor dicho, podemos ser conscientes o no. El sueño por entender el mundo se basa en dominar todos los medios, lo visible y lo invisible. Por ello mi práctica artística e investigación se ha centrado en la detección de las señales electromagnéticas emitidas por las máquinas para hacerlas perceptibles. Amplificando la señal mediante un dispositivo que aumenta el valor de la señal, las bajas frecuencias como las ondas de radio, la luz solar o la emitida por plantas y organismos vivos, se hacen perceptibles. Estas frecuencias han sido modificadas y empleadas en diferentes composiciones musicales y trabajos artísticos.

\section{Palabras clave: CAMPO ELECTROMAGNÉTICO; AUDIBLE; MÚSICA; FRECUENCIA; PERCEPCIÓN}

\section{SONEAR: VOICING, SONIFICATION AND AUDIFICATION. TRANSFORMATIONS OF THE ELECTROMAGNETIC FIELD IN ART}

\section{Abstract}

Using the everyday into art changes, currently the technology and electronic extensions who are under this framework. The transition from analog to digital has created a new work item, a non-detectable airborne material. We deal with more machines than people, and they do not speak but generate energies and vibrations, a second level of machine-user interaction. The energies flow through us and we can be sensitive or not, or rather, can be conscious or not. The dream to understand the world is based on mastering every enviroment, the visible and the invisible. Therefore my practice and research has been focused on the detection of electromagnetic signals emitted by machines to make them detectable. The signal is amplified by a device that increases the value of the signal. They are low frequencies as radio waves, the sunlight or those emitted by plants and living organisms. This frequency is modified and used in different musical compositions.

Keywords: ELECTROMAGNETIC FIELDS; AUDIBLE; MUSIC; FRECUENCY; PERCEPTIBLE

\footnotetext{
Bueno de Santiago, Alejandra. 2015. "Sonificar, sonorizar y audificar: transformaciones del campo electromagnético en el arte”. AusArt 3 (2): 236-250. D0I: 10.1387/ausart.15966
}

\section{AUSART}




\section{DEVENIR SONIDO}

"Aunque los científicos contemporáneos detectan las peculiaridades de cualquier arma mediante ordenador, los antiguos armeros tenían que detectarlas "de oído», por así decirlo, rastreando las "características expresivas» (propiedades físicas) que estos puntos atribuyen a la materia y recurriendo a sus capacidades morfogenéticas en el proceso de fabricación de un arma determinada."

(DeLanda 1991)

En ocasiones dudamos de nuestros propios sentidos e incluso no sabemos con certeza cómo sentimos las cosas, muchos mantienen la creencia de un sexto sentido. Habitualmente el sentido que nos ofrece más datos sobre el entorno es la vista. Tras las apreciaciones hechas por Martin Jay en "Regímenes escópicos de la modernidad" $(2003,221)$ nos preguntamos si la era moderna presenta uno o varios regímenes escópicos, quizás en competencia entre ellos. El concepto de régimen escópico se toma prestado de Christian Metz para conceptualizar determinaciones culturales, modos de mirar y gramáticas de la mirada que presuponen que algo tan natural como la mirada no es un proceso inocente y lleva consigo patrones culturales predeterminados. Por otra parte, se ha demostrado que la racionalidad está básicamente conectada al sentido de la vista (Daston \& Galison 2007). Solo cuando se trata de temas invisibles u ocultos, el oído se transforma y pasa de ser un órgano subestimado al sentido más idóneo para la adquisición de conocimientos. Es lo que ocurrió en el siglo XVIII con la auscultación médica del cuerpo humano y lo que sucede con los ingenieros de automoción, quienes, desde el inicio de la industria automovilística, tienen la necesidad de escuchar el sonido que hacen sus motores. En el caso de la tecnología del sónar, la reconfiguración auditiva se produjo tras la colisión del trasatlántico Titanic en 1912, un accidente que se hubiera podido evitar con medios adecuados de localización submarina, basados en ondas ultrasónicas. En los tres ejemplos, la vista no se utiliza para nada, ya que o bien es necesario mirar dentro de algo que no puede abrirse o bien uno está a oscuras. En estas situaciones entran en juego dispositivos técnicos para oír y escuchar a escondidas. La escucha puede convertirse en un modus operandi para la investigación crítica sobre temas relacionados con los media, especialmente con relación a las agencias ocultas dentro de las redes del inconsciente técnico (Thrift 2004).

Es importante retomar el concepto ritornello (Deleuze \& Guattari [1980] 2004), un género musical con una rica y rizomática historia, desarrollado principal- 
mente entre el siglo XIV y finales del XVIII. Es un diminutivo de la palabra italiana ritorno, que significa «regreso». El principio común a todo ritornello es la repetición y la iteración, lo que conecta conceptualmente este término al ritmo. Existen diferentes capas y niveles de iteración rítmica en cada proceso, ya sea en el campo de la Historia, la Geología, la Biología, la Física, la Ingeniería o la Filosofía. Una forma de que estos ritmos industriales y terrestres se vuelvan audibles es la detección electromagnética de redes digitales de datos, como Wifi o Bluetooth, pero también GSM, UMTS y otros sistemas o la detección de señales de baja frecuencia que circulan por debajo de nuestro umbral perceptivo. Dentro del campo electromagnético de las máquinas de uso común se evidencia como esa iteración rítmica se vuelve finalmente un compañero de trabajo imperceptible que debemos destapar.

Tras un análisis formal de la situación acontece el análisis epistemológico del objeto de estudio, donde se quieren analizar varios conceptos que definan el proceso transformación del mundo hacia lo sonoro a través del arte. En la filosofía deleuziana, la importancia del proceso nunca reside en los polos, en lo que fue ni en lo que será, se sitúa en el camino, donde se establecen relaciones con lo otro pero sin dejar de ser uno mismo. El concepto de devenir de Deleuze en el campo del sonido nos habla de recuperar la parte sonora que hay en cada objeto sin perder la personalidad. Devenir sonido puede ser enunciado como "sonear", proceso por el cual un elemento material-inmaterial, humano-animal, real-virtual, comienza una recuperación de los aspectos sonoros que residen en él y establece nuevas relaciones con el resto de aspectos que lo componen. El aspecto más científico hablaríamos de una sinergia entre tres procesos, la audificación, la sonorificación, y la sonificación.

La sonorización del campo electromagnético es un poco ambigua, podría ser entendido como; ponerle una banda sonora o preparar la instalación sonora para la escucha de este. En este caso es la transformación del campo electromagnético en sonido. La audificación sin embargo, consiste en convertir algo que ya era audible pero no perceptible en perceptible. En otras palabras, se trata de amplificar una señal audible hasta los rangos de la percepción auditiva de un ser humano. También tenemos la sonificación, una herramienta que permite la transformación de cualquier tipo de información en sonido. Podemos plasmar en sonido imágenes $2 \mathrm{D}$, datos de tráfico en redes de comunicaciones e incluso la información de violentos sucesos del cosmos (C.J. Hogan, The sounds of spacetime). Trabajos como el de Xenakis ${ }^{1}$ muestran cómo es posible la traslación de la música a la arquitectura. Una de sus principales obras es su diseño del Pabellón Philips de la Exposición Internacional de Bruselas de 
1958, el cual estaba basado en las mismas estructuras que su obra orquestal Metástasis de 1953-1954. La sonificación permite el trabajo inverso, transformar, por ejemplo, en sonido esas estructuras arquitectónicas.



Ilustración 1: Portada del disco de Xenakis

En el trabajos de David Cope (2004) y en el libro Máquinas modelos de música (Scwanauer \& Levitt 1993) encontramos obras sobre la música virtual y se desarrolla el concepto de lo generativo, este permite el desarrollo de un sistema de sonificación estructurado, basado en normas de composición gracias 
a las cuales pueden generarse piezas en distintos estilos musicales. Es decir, a través de este sistema generativo es posible obtener notas, duraciones, intervalos y otros elementos musicales mediante secuencias numéricas, las cuales puede representar cualquier tipo de información.

Por otro lado este proyecto atiende a una similitud con la transcodificación, término acuñado por Lev Manovich (2005), como uno de los cinco principios básicos del lenguaje de los nuevos medios. Manovich lo usa para hablar de la influencia recíproca que se establece entre lo que denomina la capa cultural y la capa informática, que una hace referencia a los textos, cuentos e historias y la segunda se centra en los procesos y lenguajes informáticos. Si bien está claro que la cultura condiciona la evolución de la tecnología, lo que Manovich nos explica en la definición de la transcodificación cultural es que la capa informática provoca en la capa cultural una transformación profunda y la sustitución de determinados conceptos y categorías por otros provenientes de la ontología informática.

Tras una valoración del cómputo de los conceptos tratados y teniendo en cuenta la hipótesis de que en todo elemento existe el componente sonoro unido al deseo de ver u oír lo que no alcanza nuestro umbral perceptivo con el objetivo de comprender nuestro mundo tecnológico y nuestra relación con él, se identifica el concepto "sonear", como el más idóneo en esta búsqueda de conocimiento a través del campo sonoro. Así como Gilles Deleuze enuncia que la importancia reside en lo que pasa, lo que atraviesa, lo que cambia, es para ello necesario cambiar el paradigma del ser por el de devenir, resaltando el proceso del cambio. Para ello es necesario establecer una lógica distinta entre sujetos y predicados que evidencie ese devenir en el que los puntos de inicio y fin queden en un segundo plano. Puede quedar ejemplificado con esta frase, el devenir sonido del campo electromagnético en vez de, el campo electromagnético deviene sonido, invirtiendo su orden y haciendo del sujeto predicado. O la segunda opción, creando un nuevo verbo, "sonear".

\subsection{CazAndo el espectro}

A raíz de este deseo, se ha desarrollado una aplicación móvil capaz de detectar y clasificar las ondas electromagnéticas mediante la implementación de un sensor en nuestros dispositivos móviles. Se propone una toma de conciencia hacia la energía que generamos. El objetivo principal es abrir las puertas a los usuarios de un campo poco explorado, la utilización del espectro electromagnético transformado en sonido en el arte. Se ofrece la posibilidad de grabar el 
sonido obtenido y poder usarlo en composiciones, instalaciones o vídeos. El propósito es que sea usado en el arte, para ello se ha creado una web donde se recogen todos los sonido recogidos hasta la fecha y así como las composiciones creadas. Los sonidos brutos son descargables ${ }^{2}$ y se indica que la intención es llegar a crear una red de artistas sonoros que empleen este medio. El micrófono consta de dos partes, un amplificador que hace posible reconocer la señal y un sensor por el que se capta la señal.

Los requisitos básicos que tiene que tener este micrófono son que tenga una conexión de tres canales, es decir un mini jack con 3 bandas en vez de con dos ya que los móviles solo poseen una entrada de mini jack que vale tanto como para auricular como para micrófono. La tercera banda es la que hace referencia al micrófono por lo que solo tendremos que tener en cuenta esta misma a la hora de hacer las conexiones. Se emplea un cable de sonido mono, pues la señal que recibimos va a ser única a excepción del empleo de dos sensores. El tipo de sensor que se emplea es un inductor, modelo 3JJJ. Es una bobina que nos permite almacenar la energía en modo de campo electromagnético.

El amplificador usado permite una adición de hasta $46 \mathrm{Db}$ en la señal de entrada. Tiene un interruptor que ofrece la posibilidad de aumentar x20 o x200 veces la entrada.

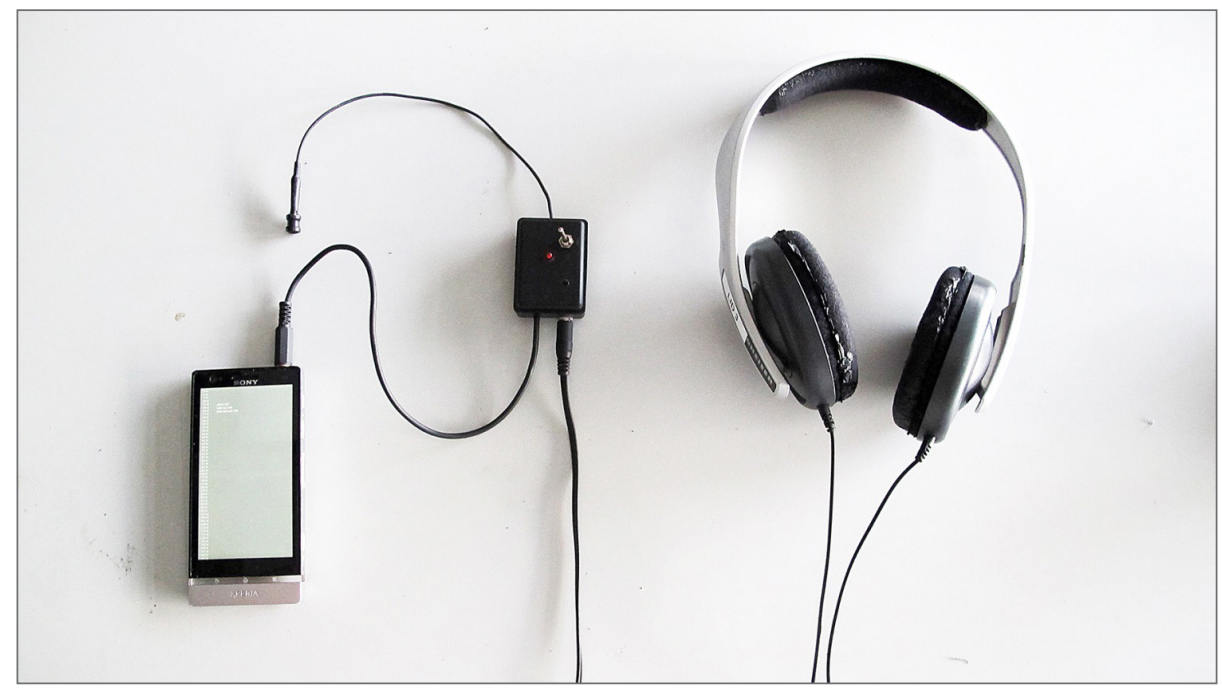

Ilustración 2: El kit del soneador, amplificador de señal, micrófono, móvil (Android) y auriculares. 




Ilustración 3: Fig. 7. Interface vista desde el emulador de aplicaciones Android en Windows.

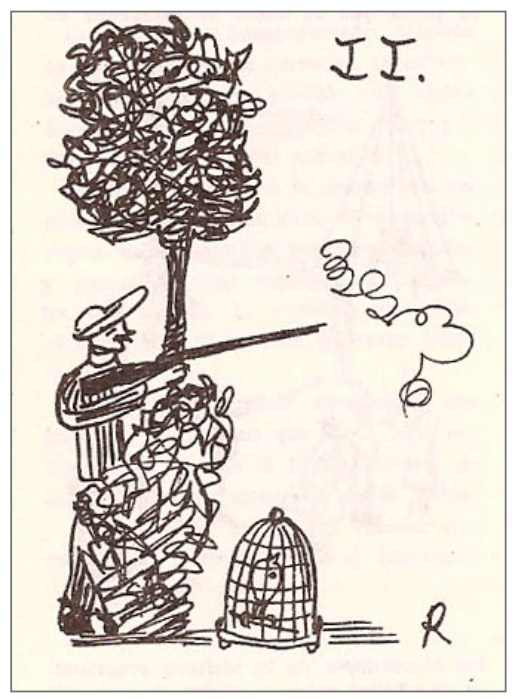

Ilustración 4: Ilustración del cuento de Ramón Gómez de la Serna.
La aplicación Catching the spectrum ${ }^{3}$ se desarrolla en Processing y el diseño de la interface consta de un diagrama gráfico en el que de $10 \mathrm{hz}$ a $20000 \mathrm{hz}$ se dibujan los niveles que van entrando marcándose con un círculo rojo los picos más altos y dando el valor en hercios. El audio puede ser captado tanto por el micrófono integrado como por la entrada de Jack con un micrófono externo. En el fondo se dibujan unas líneas que dividen el rango $y$, separado por colores se encuentran las diferentes maquinas a las que hace referencia la frecuencia. En la parte inferior se muestra la referencia de los valores, del búfer, la velocidad y el volumen.

Para el desarrollo de esta aplicación se ha contado con David Sanz Kirbis, quien optó por usar la biblioteca FFT ${ }^{4}$ haciendo posible la utilización de la biblioteca Minim en Android. La interface emplea la función de grabación de audio de Processing.org con API de Android, para desarrollar una aplicación de análisis de audio.

\subsection{LA CAZADORA DE ONDAS}

La búsqueda de señales imperceptibles intriga al ser humano desde su afán de dominar su entorno. Aquello que no vemos ni oímos produce temor e intriga. Desde los espíritus hasta los sonidos del espacio. En una conversación con Miguel Molina surgió el rescate de un cuento redactado por Ramón Gómez de la Serna llamado el cazador de ondas (1929). En él se narra la breve historia de un cazador que sale en busca de su presa con una lámpara como reclamo. Traspolamos el concepto del cuento con la idea de cazar ondas electromagnéticas en pro de la música. Generamos un nuevo concepto de productor musical, La 
cazadora de ondas. Todo nuevo movimiento artístico que se precie necesita de un icono representativo y anecdótico, una personificación que alude al concepto. Es por ello que se crea el personaje y se hace visible mediante una serie fotográfica que toma como referencia el cuento de Gómez de la Serna, donde se sustituye la lámpara por una grabadora y la escopeta se implementa con un receptor de ondas.

Estas fotografías forman parte de la metáfora del proceso de "sonear", la caza musical de registros no audibles. El trabajo compositivo se divide en dos; por un lado las que mantienen su propia naturaleza del ser y por otro lado aquellas que han sido ligeramente modificadas y acompañadas de bases electrónicas, las alienadas.

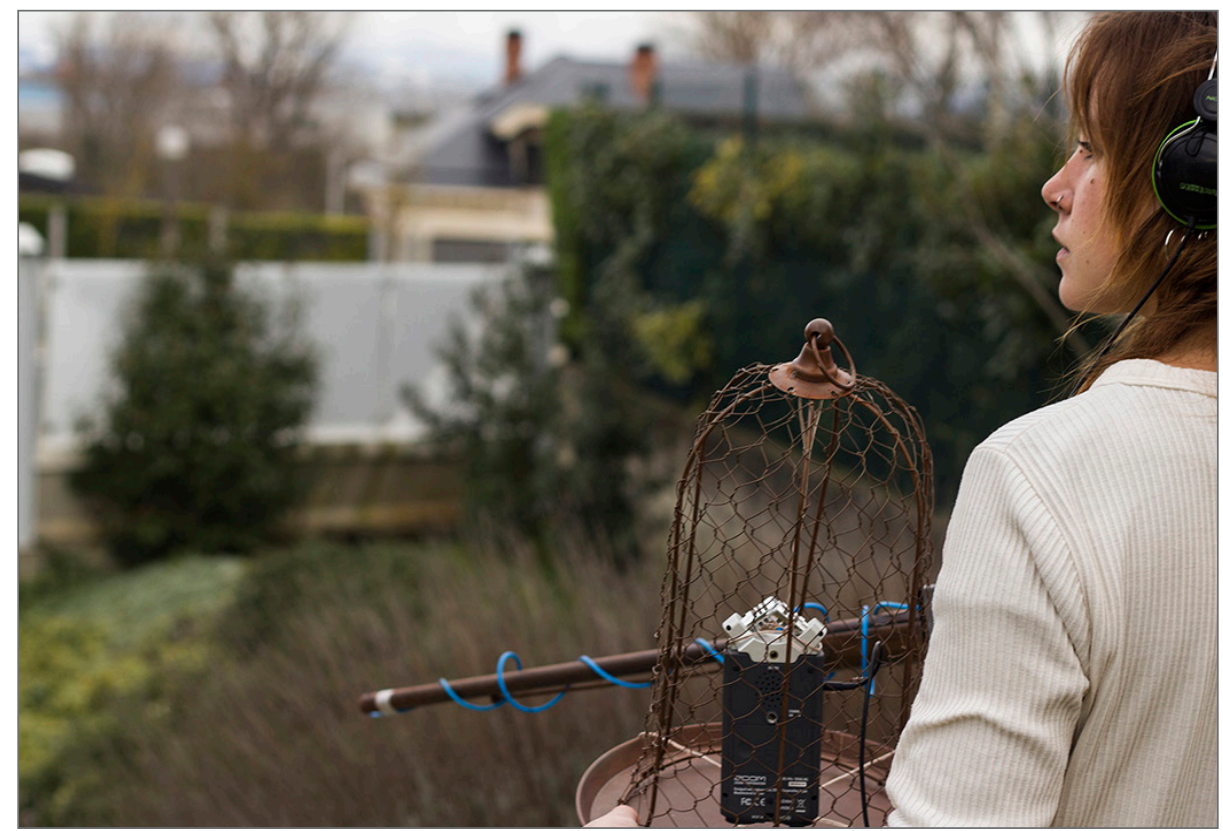

Ilustración 5: Fotografía de la cazadora de ondas, el homólogo actual de Ramón.

\section{EL SER CONSCIENTE}

Una de las inquietudes que nos abordan es saber porqué el hombre se ha empeñado en saber todo y desvelar lo que está oculto. Por una parte tenemos la frustración ante los límites de la percepción. Existe una tendencia a la gene- 
ración de un súper-hombre, mediante extensiones biónicas e implementaciones tecnológicas que le permitan la comprensión del mundo a un nivel superior. Los últimos avances tecnológicos en el campo de la medicina se centran en la creación de dispositivos que amplían la visión o el oído. Hay una historia que llama la atención: el mito de Fausto, el protagonista de una leyenda clásica alemana. Un erudito de gran éxito, pero también insatisfecho con su vida, hace un trato con el diablo intercambiando su alma por el conocimiento ilimitado y los placeres mundanos. La historia del doctor Fausto es una metáfora mítica de la lucha de todo ser humano por encontrar la luz en medio de las tinieblas. Fausto constituye un paradigma, un ejemplo de nuestro mundo interior, lleno de conflicto entre nuestros deseos egocéntricos y el anhelo de servir a algo más elevado y más grande que nosotros mismos. Aunque el mito original tiene sus raíces en el cristianismo medieval y, por lo tanto, presenta el bien y el mal de un modo más bien simplista, el mensaje trasciende cualquier doctrina religiosa específica, en particular si esta se comprende psicológicamente.

Los umbrales de percepción del ser humano son limitados en comparación con otros animales o con lo que se puede abarcar con la tecnología. José Luis Brea $\left(2007^{5}\right)$ no habla de la "episteme escópica" que se refiere a lo que se sabe en lo que se ve, en este caso lo relacionamos con lo que se oye, "aquello que puede ser conocido en aquello que puede ser oído", el terreno de lo cognoscible en lo audible. El problema que aquí se plantea es que ni siquiera somos capaces de percibir el campo electromagnético pues no hay ningún sentido tan desarrollado como para hacerlo. Es por esto que se traducen al sonido donde siguen manteniendo su cualidad inmaterial e invisible. Ahora, mediante el sonido de las ondas, podemos generar un conocimiento y consciencia sobre ellas, se puede reconocer que ciertas propiedades se mantienen en la transcodificación como son la amplitud de la onda y el tiempo. El tiempo es una cualidad muy importante en el sonido, y en ocasiones contradictoria, pues para nosotros el sonido tiene una duración, ocupa un espacio en el tiempo, pero realmente es una onda que viaja por el espacio aéreo y sólo la percibimos cuando se detiene en nuestro tímpano. Algo similar pasa con las ondas electromagnéticas.

En el texto de Brea Cambio de régimen escópico: del inconsciente óptico a la e-imagen (2007) se expone la idea de un conocimiento no conocido inscrito en lo visual, idea retomada de Walter Benjamin (1936). Se nos dice que esto puede ser desvelado por el ojo mecánico que sería la cámara fotográfica que es capaz de captar lo que no vemos o mejor dicho lo que vemos y no percibimos, aquí se hace uso de otro tipo de sistemas que realizan la misma acción 
pero con el sonido. Se enuncia que la mayoría de cosas que se nos escapan tienen que ver con el acontecer, con el devenir y es en donde reside la importancia. Pero no solo gracias al ojo u oído mecánico tenemos conocimiento de lo inconsciente, si no que gracias a las prácticas artísticas también se puede dar uno cuenta de la elucidación de la que habla Benjamin. Minoru Sato, en su obra Built in a room que hace referencia al artista Alvin Lucier y su pieza I am sitting in a room (1969), graba diferente señales y bajas frecuencias para amplificarlas y luego re-grabarlas y hacer un bucle en directo. Más actual -de 2013-, es otra pieza que también hace referencia a esta misma obra de Lucier llamada Isilean pentsatu ozen jokatu ("pensar en silencio actuar con ruido"), de Josu Rekalde, Mikel Arce y Enrike Hurtado, en ella construyen una instalación compuesta por pizarras que cubren toda una pared donde el sonido de la tiza al escribir es grabado y regrabado constantemente.

El punto que se quiere alcanzar es la generación de conocimiento desde la consciencia de lo imperceptible, una situación que las máquinas no pueden generar: es el ser humano quien, gracias a ellas, consigue reflexionar y llegar a formar teorías más completas que ayuden a comprender su entorno.

\section{LOS RUIDISTAS DEL SIGLO XXI}

Las conexiones o relaciones a otras teorías y tendencias que esta investigación y sus trabajos prácticos pueden tener son varias. En primer lugar se debe citar a Luigi Russolo y el manifiesto El arte de los ruidos (1998). Se puede concretar que estos cazadores de ondas son los nuevos ruidistas del siglo XXI.

Russolo hace referencia a una vida dominada por el silencio y carente de ruidos hasta el S.XIX con la creación de las máquinas. Pero aun así se vive todavía en sordina. Lo que estas máquinas son capaces de generar va más allá del sonido generado por la energía cinética y el choque entre elementos, lo cual somos capaces de ver y oír. Hay una gran variedad de sonidos generados por otras energías provenientes de las máquinas que enriquecen el panorama de los ruidos. Si con la introducción de la maquinaria en el sector agrícola y en los hogares se produjo una revolución en el campo artístico-sonoro, ahora asistimos a una segunda revolución del arte de los ruidos. 
Pasamos del estado puro del sonido que quedó carente de interés, a los ruidos que comenzaron a formar una nueva paleta sonora pretendiendo aglutinar los sonidos más anti armónicos, diferentes y duros para el oído. Pero estos sonidos cada vez se hacen más familiares, y es que el ser humano tiene una gran capacidad de absorción y asimilación y en seguida todo pierde interés, necesita el cambio, el dinamismo, emociones nuevas, por lo que siempre está en búsqueda de lo diferente, ¿quién dijo que ser raro era algo malo?. Así pues el ser humano tiene que salir de caza a por el nuevo sonido, e intentar encontrar nuevos sonidos disonantes y poco convencionales.

Los aparatos y máquinas de última generación cada vez buscan ser más silenciosos, los futuristas estarían tirándose de los pelos, pero esa sofisticación en el diseño y circuitaje demanda una mayor complejidad electrónica que genera diferentes corrientes y concentraciones de energía. Estas máquinas en muchas ocasiones son para el hombre una extensión de su cuerpo, para acceder donde el ser humano no es capaz de llegar. Por ejemplo, ayudan al aumento de señal tanto gráfica como sonora. Por un lado podemos ver gracias a la velocidad de captura de vídeo imágenes que se escapan a nuestro ojo y por otro lado mediante la amplificación sonora somos capaces de oír lo que creíamos silencio.

Son cosas que ya existen, son los nuevos ruidos de las máquinas, imperceptibles por nuestro tímpano, como los generados por el campo electromagnético. Si nuestro oído ya se educó para esta primera evolución de los sonidos y su aplicación musical, la asimilación de la segunda evolución ha de ser mucho más fácil, realmente nada nos sorprende hoy en día, la avalancha de información nos deja insensibles.

En el episodio 7 del documental El impacto de lo nuevo presentado por Robert Hughes (1980) se tratan los símbolos de la cultura moderna que reflejan el poder de los medios de comunicación, publicidad, radio y televisión, y cómo se convirtieron en tema para los artistas. En este documento se encuentran dos citas muy interesantes que hablan sobre la situación que se crea en este contexto. La primera hace referencia a Walter Benjamin y dice: "para un niño educado entre la algarabía de las señales iba a resultarle duro y quizá imposible encontrar el camino de vuelta al silencio que exige un libro". Pero esto fue hace más de 50 años, y el panorama que nos acontece sugiere nuevas formas de conocimiento que ya no están en los libros y que son perceptibles por muchos sentidos: hay que estar abierto a los nuevos estímulos. El silencio ha quedado reducido a un concepto que se encierra en una sala con paredes acolchadas. 
El libro se ha quedado obsoleto ante el multiverso y nuestras herramientas se han multiplicado, siendo tal la cantidad de elementos a transformar o subvertir que, hasta el duchampiano más creativo se vería ahogado. Otro comentario interesante que encontramos en el documental corresponde a Marshall McLuhan: "ante un alud de información como este, cuando se rodea a la gente de información eléctrica la sobrecarga es fantástica y la única actitud que queda es la sumisión". Ya no estamos en actitud combativa ante los medios como enemigos del sistema, sino que nuestra posición es la de aprovechar hasta las desventajas de estos. Este desbordamiento de energía genera una dimensión sonora no explorada que sigue in crescendo.

\section{EL FUTURO MUSICAL}

Ahora que somos conscientes de que la variedad de sonidos ha aumentado con los medios, el trabajo a realizar cada día se duplica. Se habla de la música convencional como aburrida y gastada. El ruido y el sonido se diferencian en regularidad, tiempo e intensidad. Estos ruidos electromagnéticos se caracterizan por tener un ritmo en base al envío de energía, por lo que generan una composición en constante repetición que pasa de un punto de alta intensidad a otro, o en ocasiones es un envío uniforme de energía.

Estos nuevos sonidos se vuelven a presentar confusos y sorprendentes, y si la característica del ruido es que nos remite a la vida, estos "sub-ruidos" nos remiten a otra realidad todavía desconocida. En su día se crearon seis familias de ruidos: los sonidos creados por máquinas, animales, objetos, naturaleza y 'sucesos de la vida', subdivididos en dos: un primer grupo que engloba susurros, murmullos, refunfuños, rumores, gorgoteos y un segundo que tiene en cuenta los silbidos, pitidos y bufidos. En esta ocasión se han creado otras familias asociadas a esta nueva categoría de "sub-ruidos", que se dividen en tres: la de las máquinas domésticas, la de los sistemas de conexión Wifi y las de la maquinaria industrial.

Dentro de este espectro desconocido también existen otros grupos de energías transformables a tener en cuenta, como aquellos que se encuentran en el espacio. La artista malagueña Regina de Miguel realiza un trabajo artístico en colaboración con el Instituto Neerlandés de Radioastronomía, que se ocupa del estudio de las ondas de radio emitidas por los cuerpos celestes. La 
captación de las ondas provenientes de Sagitario A, un agujero negro masivo situado en el centro de la Vía Láctea, permitió realizar posteriormente un paisaje sonoro. Teniendo en cuenta la perdurabilidad en el tiempo de las ondas, resulta complicado definir la antigüedad de estos sonidos. Lo que está claro es que siempre pertenecen al pasado.

Pero el espectro hoy día se nos vuelve inalcanzable. Si seguimos ahondando nos encontraremos con el trabajo de Leslei García, en un proyecto en el que usa traductores y amplificadores para permitirnos escuchar a las plantas. Así nuestra base de datos de sub-ruidos sigue creciendo y nuestros oídos están en perpetuo proceso de aprendizaje, reeducandose para la asimilación de estas señales.

Todas ellas pueden ser recibidas desde la aplicación Catching de spectrum disponible para Android. dependiendo del tipo de sensor que utilizemos, también podremos encontrar versiones desarrolladas por otros investigadores para diferentes sistemas operativos como Iphone. Aaron Ramussen, inventor y creativo, desarrolló una aplicación llamada Mr Gosth, dedicada a la búsqueda de señales ocultas o "fantasmas". La proliferación de investigaciones acerca de las ondas electromagnéticas ha ido creciendo a medida que surgen diferentes preocupaciones con respecto a la salud. Pero son los artistas que de un modo distinto al habitual generan dicha sensibilización, bien sea directa o indirectamente.

Los sonidos compilados durante esta investigación se sitúan en el campo electroacústico y conforman una nueva paleta para los creadores musicales y artistas. La base de datos sonora se amplía notoriamente y parecería necesaria una re-categorización constante para dar visibilidad y riqueza, y no caer en la monotonía sonora.

\section{Referencias}

Benjamin, Walter. (1936) 2003. La obra de arte en la época de la reproductibilidad técnica. Traducción de Andrés E. Weikert. México DF: Ítaca

Brea, José Luis. 2007. "Cambio de régimen escópico: del inconsciente óptico a la e-image". Número especial “¿Un diferendo ‘Arte’?”. Estudios Visuales: Ensayo, Teoría y Crítica de la Cultura Visual y el Arte Contemporáneo 4

Cope, David. 2004. Virtual music: Computer synthesis of musical style. Cambridge MA: MIT

Daston, Lorraine \& Peter Galison. 2007. Objectivity. New York: Zone Books 
DeLanda, Manuel. 1991. War in the age of intelligent machines. Michigan. Zone Books

Deleuze, Gilles \& Félix Guattari. (1980) 2004. Mil mesetas: Capitalismo y esquizofrenia. Traducción de José Vázquez Pérez. Valencia: Pre-Textos

Deleuze, Gilles (1972) 2009. El anti-Edipo. Traducción de Francisco Monge. Barcelona: Paidós

Didi-Huberman, George. 1997. Lo que vemos, lo que nos mira. Traducción Horacio Pons Buenos Aires: Manantial

Gómez de la Serna, Ramón. (1929) 1987. "El circo de las ondas" En Radiorramonismo: Antología y estudio de textos radiofónicos de Ramón Gómez de la Serna, de Jose Augusto Ventín Pereira Madrid: Univ. Complutense

Hughes, Robert. 1980. El impacto de lo nuevo. Ep. 7, Cultura como naturaleza [The Shock of the New. Episode 7, Culture as Nature]. Escrito y presentado por R. Hughes para la BBC2. Vídeo de Youtube, 59:11 https://www.youtube.com/watch?v=0b7NFerPRAs

Jay, Martin. (1993) 2003 “Regímenes escópicos de la modernidad”. En Campos de fuerza: Entre la historia intelectual y la crítica cultural, traducción de Alcira Bixio, 221. Barcelona: Paidós

- (1993) 2007. Ojos abatidos. La denigración de la visión en el pensamiento francés del siglo $X X$. Traducción Francisco López Martín. Madrid: Akal

Krauss, Rosalind. 1997. El inconsciente óptico. Traducción de J. Miguel Esteban Cloquell. Madrid: Tecnos

Manovich, Lev. 2005 El lenguaje de los nuevos medios de comunicación: La imagen en la era digital. Traducción de Óscar Fontrodona. Barcelona. Paidós

Molina Alarcón, Miguel. 2008. "El arte sonoro". Itamar 1: 213-34 http://es.scribd.com/ doc/24370658/El-Arte-Sonoro-Articulo-de-Miguel-Molina-Alarcon

Robinson, Julia E. 2009. "The Anarchy of Silence: John Cage and Experimental Art", viernes 23 oct. Conferencia de la comisaria de la exposición La anarquía del silencio: John Cage y el arte experimental (23 oct. 2009-10 ene. 2010). Audio, 49:23, www.macba.cat/es/julia-e-robinson

Russolo, Luigi. (1916) 1998. El arte de los ruidos. Cuenca: Centro de Creación Experimental UCLM

Sontag, Susan. (1969) 2005. "La estética del silencio". En Estilos radicales, trad. E. Goligorsky, 13-60. Buenos Aires: Punto de Lectura

Stephan M. Scwanauer \& David A. Levitt, eds. 1993. Machine Models of Music. Cambridge MA: MIT

Thrift, Nigel. 2004. "Remembering the technological unconscious by foregrounding knowledges of position". Enviroment and planning D: Society and Space 22: 175-90

Notas

${ }^{1}$ Xenakis fue un integrantes del CEMAM (Centre d'Études de Mathématique et Automatique Musicales), instituto dedicado al estudio de aplicaciones informáticas en la música. Allí Xenakis concibió y desarrolló el sistema $\underline{\text { UPIC }}$, que permite la realización sonora directa de la notación gráfica que se efectúa sobre una tablilla. 
${ }^{2}$ Enlace para la escucha y la descarga de los sonidos y las piezas musicales: https://soundcloud.com/alejandrabueno

${ }^{3}$ Toda la información necesaria para el desarrollo de la aplicación está en la web: http://therandomlab.blogspot.com.es/2013/05/fft-audio-frequency-analysis-with

${ }^{4}$ FFT es la abreviatura usual (del inglés Fast Fourier Transform) de un eficiente algoritmo que permite calcular la transformada de Fourier discreta (DFT) y su inversa. La FFT es de gran importancia en una amplia variedad de aplicaciones, desde el tratamiento digital de señales y filtrado digital en general a la resolución de ecuaciones de derivadas parciales o los algoritmos de multiplicación rápida de grandes enteros.

${ }^{5}$ En el art. "Cambio de régimen escópico: del inconsciente óptico a la e-image" (Estudios Visuales 4, 2007), Brea distingue tres eras de la imagen: material, fílmica y e-imagen. A su vez distingue también la imagen inconsciente, que opera haciendo cognoscible lo que no es visible, de la imagen electrónica, que opera desde lo gregario, la red, la productividad y el concepto de fantasma. 